\title{
Functionalization of 3,4,6-Tri-O-acetyl-D-Glucal with potassium organotrifluoroborate salts: Synthesis of 1,2,3-triazoles
}

\author{
Nathália C. S. Silva ${ }^{* 1}$ (PG), Flávia G. Manarin ${ }^{1}(P Q)$, Hélio A. Stefani ${ }^{1}(P Q)$, Diogo S. \\ Lüdtke $^{2}(P Q)$.
}

${ }^{1}$ Departamento de Farmácia, Faculdade de Ciências Farmacêuticas, Universidade de São Paulo, São Paulo, SP, Brasil. ${ }^{2}$ Instituto de Química, Universidade Federal do Rio Grande do Sul, Porto Alegre, RS, Brasil.

*nathycris@usp.br

Keywords: 3,4,6-Tri-O-acetyl-D-Glucal, 1,2,3-triazole, click chemistry.

\section{INTRODUCTION}

C-glycosides are compounds of extreme interest because they occur in products with relevant biological properties., ${ }^{1,2}$ Moreover, they are interesting synthetic building blocks for further functionalizations. ${ }^{3}$

In this context, the use of potassium organotrifluoroborates salts represent an interesting strategy for the synthesis of unsaturated pyranoside derivatives. The goal of this work is the functionalization of a derivative of $D$-glucose by Ferrier rearrangement, and then the preparation of 1,2,3-triazoles, obtaining products with great structural diversity.

\section{RESULTS AND DISCUSSION}

We were able to produce the C-glycoside functionalized at position two, which was possible through the use of a Lewis acid in the Ferrier rearrangement, in yields ranging from 58 to $89 \%$ (Scheme 1). ${ }^{4}$

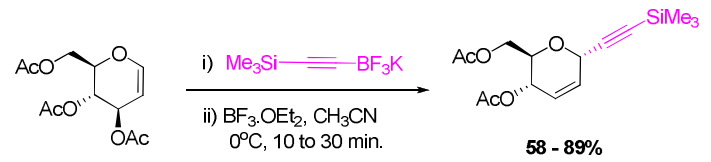

Scheme 1. The Ferrier rearrangement

The functionalized C-glycoside was used as the starting material for the cycloaddition reactions of azide-acetylene using $\mathrm{Cul}$ as copper source and ultrasonic waves as an energy source, with TBAF as a desilylation agent, with or without the addition of 1,1,4,7,7-Pentamethyldiethylenetriamine (PMDETA) (Scheme 2).

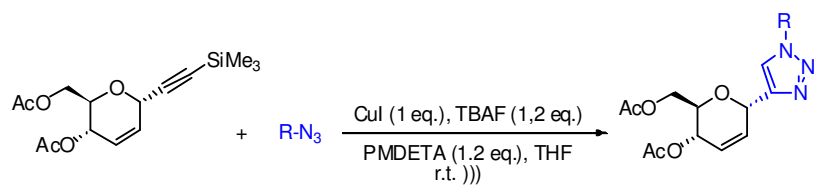

Scheme 2. The cycloaddition reaction
In order to demonstrate the efficiency of the reaction, we explored its generality. This way, several novel compounds were synthesized with yields ranging from 38 to $74 \%$ (Figure 1 ).<smiles>COCC1OC(c2nnnn2-c2ccc(C)cc2[N+](=O)[O-])C=CC1O</smiles>

$38 \%$
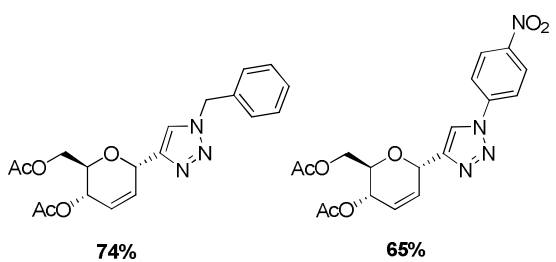
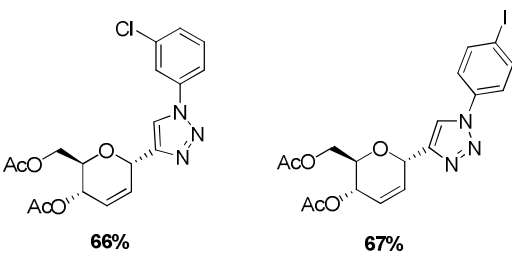

Figure 1. Some examples of 1,2,3-triazoles

\section{CONCLUSION}

We developed a synthetic methodology for the functionalization of 3,4,6-tri- $O$-acetyl- $D$-glucal with success. The reaction of cycloaddition with copper through a simple and efficient strategy allowed the preparation of a series of compounds with high structural diversity, and two heterocyclic rings having different substituents.

\section{ACKNOWLEDGEMENTS}

The authors would like to thank CNPq (300.613/2007-5) and FAPESP (2007/54904-2), (2010/15677-8).

\section{REFERENCES}

${ }^{1}$ Subadolnik, R. J. Nucleoside Antibiotics; Wiley-Interscience: New York, 1970.

${ }^{2}$ a)Faul, M. M.; Huff, B. E. Chem. Rev. 2000, 100, 2407. b)Kirshning, A.; Chen, G. W.; Drager, G.; Schuberth, I.; Tietze, L. Bioorg. Med. Chem. 2000, 8, 2347.

${ }^{3}$ a)Yeager, A. R.; Min, G. K.; Porco Jr., J. A.; Schaus, S. E. Org. Lett. 2006, 8, 5065.b)Lubin-Germain, N.; Hallonet, A.; Huguenol, F.; Palmier, S.; Uziel, J.; Augé, J. Org. Lett. 2007, 9, 3679.

${ }^{4}$ Vieira, A. S.; Fiorante, P. F.; Hough, T. L. S.; Ferreira, F. P.; Lüdtke, D. S.; Stefani, H. A. Org. Lett. 2008, 10, 5215. 